\title{
Modelling dual-channel closed-loop supply chain considering production diseconomies
}

\author{
Shan Liu ${ }^{1}$, Yan Xing ${ }^{1}$, Fengmin Yao, ${ }^{1, *}$, and Dongyan Chen ${ }^{1,2}$ \\ ${ }^{1}$ School of Economics and Management, Harbin University of Science and Technology, Harbin \\ 150080, China \\ ${ }^{2}$ Scienc School of Science, Harbin University of Science and Technology, Harbin 150080, China
}

\begin{abstract}
This paper studies the pricing selection and coordination strategies for dual-channel closed-loop supply chain (CLSC) considering production diseconomies. Under the centralized and decentralized decision-making, the decision models of CLSC of retailer recycling was constructed, the effects of the manufacturer's production diseconomy and the sales competition between manufacturer and retailer on new product pricing and waste product recycling were analysed, the optimal pricing strategy of dual-channel CLSC was given, and a "two-part tariff" coordination contract was established based on centralized decisionmaking. The results indicate that the profits of each member are negatively correlated with the production diseconomy and positively correlated with the degree of sales competition, the direct sales volume of manufacturer is always more than twice that of retailer, and the stronger the competition degree is, the more obvious the advantage is. Further, within the range of contract parameters that the dominant manufacturer and retailer are willing to accept, the "two-part tariff" contract can effectively realize the coordination of dual-channel CLSC.
\end{abstract}

\section{Introduction}

In recent years, with the emergence of a large number of waste products and the increasingly serious problem of environmental pollution, closed-loop supply chain management (CLSCM) has attracted extensive attention from industry and academia ${ }^{[1]}$. For example, Xerox can save $40 \%-65 \%$ of its manufacturing costs annually by implementing trade in and remanufacturing. Volkswagen can save $70 \%$ of manufacturing costs by recycling engines and parts. Therefore, the implementation of CLSCM helps to reduce energy consumption and realize sustainable development of economy and environment.

However, many enterprises are growing in scale, and a series of expansion and merger activities are frequently performed to seize market share. These business activities may lead to different degrees of decentralization in the organizational structure of enterprises, that is, the so-called phenomenon of production diseconomies. For example, P \& G in the United States and Daewoo Heavy Industry in South Korea have all experienced production diseconomies such as rising production costs and declining profits due to their rapid

${ }^{*}$ Corresponding author: fengmin_yao@hrbust.edu.cn 
expansion of production scale. How to effectively solve this difficult problem has aroused widespread concern of scholars at home and abroad. Mollick and Rawley made an in-depth study on the impact of diseconomies of production scale on enterprises ${ }^{[2-3]}$. Based on chain competition supply chain structure, Ha studied the impact of production diseconomies on retailer information sharing ${ }^{[4]}$.

The above studies are all based on the positive supply chain structure. At present, many enterprises implement CLSCM and carry out dual-channel marketing mode, and many scholars have also conducted in-depth studies on this issue. Zheng et al. analyzed the influence of channel competition and power structure on the optimal pricing decision of CLSC under two conditions of information symmetry and asymmetry ${ }^{[5]}$. Xie et al. discussed pricing and service strategy of dual-channel CLSC under benefit-cost sharing contract $^{[6]}$. He et al. studied the optimal pricing decision of dual-channel CLSC in which retailers sell new products and third parties sell remanufactured products based on government subsidies ${ }^{[7]}$. However, the above studies rarely study the pricing and coordination strategy of dual-channel CLSC with production diseconomies.

To sum up, this paper constructs the decision model of CLSC under centralized and decentralized decision respectively, and the optimal decision of each member enterprise and the whole system in the dual-channel CLSC with production diseconomies is given. Then, based on the equilibrium result of centralized decision, a two-part pricing contract is designed to coordinate the CLSC, and the range of contract parameters is obtained.

\section{Problem description and basic assumptions}

We assume the dual-channel CLSC composed of a manufacturer and a retailer. The manufacturer is the channel leader, and both of them are risk neutral ${ }^{[8]}$. In closed-loop supply chain, manufacturer sets up direct and retail dual channels to sell products in the market. the retailer is responsible for the sale and recycling of waste products, and the manufacturer processes and remanufactures the recycled waste products. The manufacturer has the characteristics of production diseconomies. (assuming that there is no difference between the new product and the remanufactured product ${ }^{[8]}$ ).

In the forward supply chain, referring to the research of literature [5], it is assumed that the market demand functions of manufacturer's direct sales and retailer's distribution are respectively $q_{d}=a-p_{d}+\beta p_{r}, q_{r}=a-p_{r}+\beta p_{d}, a$ is the potential market capacity, $p_{d}$ is the direct price set by the manufacturer, $p_{r}$ is the retail price set by the retailer (distribution price), and $\beta$ is the cross-price elasticity coefficient between the two sales channels, assuming that $0<\beta<1$.

In the reverse supply chain, refer to the study of literature [8], it is assumed that the collecting rate of retailer is $\tau_{r}=\sqrt{I_{r}^{*} / k}, I_{r}^{*}$ is the effective cost of collector $i, k>0$ is the scale parameter, which represents the difficulty of collecting waste products.

Referring to the research in literature [4], we assume that the total production cost of manufacturer with production diseconomies is $c(q)=b q^{2}, b>0$ is the coefficient of production diseconomies, and its size describes the degree of production diseconomies. $q$ is the number of products produced by the manufacturer, so the total production is $q=q_{d}+q_{r}$. Other variables are as follows.

$w$ is the wholesale price manufacturer; $c_{m}$ and $c_{r}$ respectively is the manufacturer's unit production cost and unit remanufacturing cost. In order to ensure that remanufacturing 
is meaningful to the manufacturer, it is assumed that $\Delta=c_{m}-c_{r}>0$ is the manufacturer's unit income in the remanufacturing process of waste products. $c(F)=F \tau_{r}$ is the cooperation fee (transfer payment) paid by the manufacturer to the retailer. Where, $F$ is the total payment by the manufacturer to the retailer when the collecting rate of waste products of the retailer is $1 . \pi_{x}$ is the profits obtained by member enterprises, and $x=\{m, r, s\}$ represents the manufacturer, retailer and the whole system respectively.

\section{The optimal decision of dual-channel CLSC under centralized decision ( $S$ model)}

In order to further study the coordination problem of dual-channel CLSC with production diseconomies, the optimal decision-making problem of centralized CLSC is considered, At this time, the manufacturer and the retailer as the same decision-making subject jointly determine the direct price $p_{d}$, the retail price $p_{r}$ and the collecting rate $\tau_{r}$. Then the total profit function of the CLSC can be expressed as

$$
\pi_{s}^{S}\left(p_{d}, p_{r}, \tau_{r}\right)=\left(p_{d}-c_{m}\right) q_{d}+\left(p_{r}-c_{m}\right) q_{r}+\Delta \tau_{r}\left(q_{d}+q_{r}\right)-b\left(q_{d}+q_{r}\right)^{2}-k \tau_{r}^{2}
$$

Lemma 1 When the scale parameter $k$ satisfies $k>\frac{\Delta\left(a-(1-\beta) c_{m}+(1-\beta) \Delta\right)}{2(1+2 b(1-\beta))}$, the model $S$ has a unique optimal solution, the results are as follows: $p_{d}^{s^{*}}=p_{r}^{s^{*}}=\frac{4 k a b(1-\beta)+a\left(k-(1-\beta) \Delta^{2}\right)+k c_{m}(1-\beta)}{(1-\beta)\left(4 k b(1-\beta)+2 k-(1-\beta) \Delta^{2}\right)}, \tau_{r}^{S^{*}}=\frac{\Delta\left(a-(1-\beta) c_{m}\right)}{4 k b(1-\beta)+2 k-(1-\beta) \Delta^{2}}$ $q_{d}^{S^{*}}=q_{r}^{S^{*}}=\frac{k\left(a-(1-\beta) c_{m}\right)}{4 k b(1-\beta)+2 k-(1-\beta) \Delta^{2}}, \pi_{s}^{S^{*}}=\frac{k\left(a-(1-\beta) c_{m}\right)^{2}}{(1-\beta)\left(4 k b(1-\beta)+2 k-(1-\beta) \Delta^{2}\right)}$.

Conclusion 1 In a dual-channel CLSC considering production diseconomies, under centralized decision-making, $p_{d}^{S^{*}}=p_{r}^{S^{*}}, q_{d}^{S^{*}}=q_{r}^{S^{*}}$.

Conclusion 1 shows that, under the centralized decision of dual-channel CLSC, the optimal direct price is always equal to the optimal retail price, and the market demand under the two sales channels is also the same. In reality, in order to expand the market demand for products and enhance the competitiveness of enterprises, many large enterprises adopt online and offline dual sales channels. In order to avoid the trouble caused by price difference to consumers, enterprises usually adopt the strategy of uniform pricing, which further shows that the theory is consistent with the reality.

\section{The optimal decision of dual-channel CLSC under decentralized decision ( $R$ model)}

When the CLSC members adopt decentralized decision-making under the structure of retailer's recycling channel, the decision-making sequence as follows: the manufacturer first announces the wholesale price $w$, the direct price $p_{d}$ and the transfer payment $F$; the retailer then determines the retail price $p_{r}$ and the collecting rate $\tau_{r}$ according to the 
manufacturer's decision variable. In this case, the profit function of the manufacturer and the retailer in the CLSC can be expressed as

$$
\begin{gathered}
\pi_{m}^{R}\left(w, p_{d}, F\right)=\left(p_{d}-c_{m}\right) q_{d}+\left(w-c_{m}\right) q_{r}+\Delta \tau_{r}\left(q_{d}+q_{r}\right)-b\left(q_{d}+q_{r}\right)^{2}-F \tau_{r} \\
\pi_{r}^{R}\left(p_{r}, \tau_{r}\right)=\left(p_{r}-w\right) q_{r}+F \tau_{r}-k \tau_{r}^{2}
\end{gathered}
$$

Lemma 2 When the scale parameter $k$ satisfies $k>\frac{\Delta(3+\beta)\left(a-(1-\beta) c_{m}+(1-\beta) \Delta\right)}{8(2+b(1-\beta)(3+\beta))}$, the model $R$ has a unique optimal solution, the results are as follows:

The manufacturer's optimal decisions are $w^{R^{*}}=\frac{8 k a b A_{1} A_{3}+a \Delta_{1}+8 k c_{m} A_{1}}{A_{1}\left(8 k b A_{1} A_{3}+\Delta_{2}\right)}$, $p_{d}^{R^{*}}=\frac{8 k a b A_{1} A_{3}+a \Delta_{1}+8 k c_{m} A_{1}}{A_{1}\left(8 k b A_{1} A_{3}+\Delta_{2}\right)}, F^{R^{*}}=\frac{2 k \Delta A_{3}\left(a-A_{1} c_{m}\right)}{8 k b A_{1} A_{3}+\Delta_{2}}$. The retailer's optimal decisions are $p_{r}^{R *}=\frac{8 k a b A_{1} A_{3}+a \Delta_{3}+4 k c_{m} A_{4}}{A_{1}\left(8 k b A_{1} A_{3}+\Delta_{2}\right)}, \tau_{r}^{R^{*}}=\frac{\Delta A_{3}\left(a-A_{1} c_{m}\right)}{8 k b A_{1} A_{3}+\Delta_{2}}$. The maximum direct sales volume and distribution volume of the products are $q_{d}^{R *}=\frac{4 k A_{2}\left(a-A_{1} c_{m}\right)}{8 k b A_{1} A_{3}+\Delta_{2}}, q_{r}^{R *}=\frac{4 k\left(a-A_{1} c_{m}\right)}{8 k b A_{1} A_{3}+\Delta_{2}}$. The profits of manufacturer, retailer and the system are $\pi_{m}^{R *}=\frac{2 k A_{3}\left(a-A_{1} c_{m}\right)^{2}}{A_{1}\left(8 k b A_{1} A_{3}+\Delta_{2}\right)}$, $\pi_{r}^{R *}=\frac{k\left(16 k+A_{3}^{2} \Delta^{2}\right)\left(a-A_{1} c_{m}\right)^{2}}{\left(8 k b A_{1} A_{3}+\Delta_{2}\right)^{2}}, \pi_{s}^{R *}=\frac{k\left(16 k b A_{1} A_{3}^{2}+\Delta_{4}\right)\left(a-A_{1} c_{m}\right)^{2}}{A_{1}\left(8 k b A_{1} A_{3}+\Delta_{2}\right)^{2}}$.

Where, $1-\beta=A_{1}, 2+\beta=A_{2}, 3+\beta=A_{3}, 1-\beta^{2}=A_{4} .8 k-A_{1} A_{3} \Delta^{2}=\Delta_{1}, 16 k-A_{1} A_{3} \Delta^{2}=\Delta_{2}$, $4 k A_{2}-A_{1} A_{3} \Delta^{2}=\Delta_{3} \quad, \quad 16 k A_{6}-A_{1} A_{3}^{2} \Delta^{2}=\Delta_{4} \quad$, under the assumption of scale parameter $k, \Delta_{1}, \Delta_{2}, \ldots, \Delta_{4}>0$.

Conclusion 2 Under decentralized decision-making, $w^{R^{*}}=p_{d}^{R^{*}}<p_{r}^{R^{*}}, q_{d}^{R^{*}} / q_{r}^{R^{*}}=2+\beta$.

Conclusion 2 shows that, under decentralized decision, the wholesale price is always equal to its direct price. For retailer, in order to obtain certain benefits, its retail price is bound to be higher than the wholesale price and the direct selling price, which will lead to consumers' preference for manufacturer's direct channels. Further, the direct sales volume of products is more than twice that of retail sales, and with the enhancement of channel competition between them, the manufacturer's direct channel advantage is more obvious. This is because, as the channel leader of the CLSC, the manufacturer has a greater voice and stronger decision ability, which has a great impact on the retailer's decision.

Conclusion 3 By comparing the equilibrium results under centralized and decentralized models, $p_{d}^{R^{*}}>p_{d}^{S^{*}}, p_{r}^{R^{*}}>p_{r}^{S^{*}}, q_{d}^{R^{*}}<q_{d}^{S^{*}}, q_{r}^{R^{*}}<q_{r}^{S^{*}}, \tau_{r}^{R^{*}}<\tau_{s}^{S^{*}}, \pi_{s}^{R^{*}}<\pi_{s}^{S^{*}}$.

Conclusion 3 shows that, compared with decentralized decision, the direct and retail prices of products under centralized decision are lower, the market demand of products and the recovery rate of waste products are higher, and the overall profit of CLSC under centralized decision-making is always higher than that under decentralized decision-making.

In fact, decentralized decision making will cause the CLSC system to produce a "double marginal" effect, resulting in the loss of the total profit of the whole CLSC system. 


\section{Coordination of dual-channel CLSC under production diseconomies ( $C R$ model)}

Decentralized decision-making will cause the "double marginal" effect of CLSC system, therefore, this section mainly adopts the traditional two-part tariff contract to achieve the coordination of dial-channel CLSC. The specific coordination process is as follows:

The dominant manufacturer will provide a contract $\left(w^{C R^{*}}, F^{C R^{*}}, f^{C R^{*}}\right)$ to the retailer, where $w^{C R^{*}}$ is the wholesale price of the manufacturer, $F^{C R^{*}}$ is the transfer payment provided by the manufacturer to the retailer, and $f^{C R^{*}}$ is a fixed compensation fee paid by the retailer to the manufacturer. Under contract $\left(w^{C R^{*}}, F^{C R^{*}}, f^{C R^{*}}\right)$, the profit function of manufacturer and retailer is transformed into

$$
\begin{gathered}
\pi_{m}^{C R}\left(w, p_{d}, F\right)=\left(p_{d}-c_{m}\right) q_{d}+\left(w-c_{m}\right) q_{r}+\Delta \tau_{r}\left(q_{d}+q_{r}\right)-b\left(q_{d}+q_{r}\right)^{2}-F \tau_{r}+f \\
\pi_{r}^{C R}\left(p_{r}, \tau_{r}, f\right)=\left(p_{r}-w\right) q_{r}+F \tau_{r}-k \tau_{r}^{2}-f
\end{gathered}
$$

$$
\begin{aligned}
& \text { s.t. } \\
& \left\{\begin{array}{l}
\left(p_{d}-c_{m}\right) q_{d}+\left(w-c_{m}\right) q_{r}+\Delta \tau_{r}\left(q_{d}+q_{r}\right)-b\left(q_{d}+q_{r}\right)^{2}-F \tau_{r}+f \geq \pi_{m}^{R^{*}} \\
\left(p_{r}-w\right) q_{r}+F \tau_{r}-k \tau_{r}^{2}-f \geq \pi_{r}^{R^{*}} \\
p_{r}^{C R^{*}}=p_{r}^{S^{*}}=p_{d}^{C R^{*}}=p_{d}^{S^{*}}, \tau_{r}^{C R^{*}}=\tau_{s}^{S^{*}}
\end{array}\right.
\end{aligned}
$$

By solving the model under the above constraints, the wholesale price and transfer payment of the manufacturer under contract $\left(w^{C R^{*}}, F^{C R^{*}}, f^{C R^{*}}\right)$ can be obtained as $w^{C R^{*}}=\frac{a b k+a(1-\beta)\left(4 k b-\Delta^{2}\right)+k c_{m}(1-\beta)(2-\beta)}{(1-\beta)\left(2 k+(1-\beta)\left(4 k b-\Delta^{2}\right)\right)}, F^{C R^{*}}=\frac{2 k \Delta\left(a-(1-\beta) c_{m}\right)}{2 k+(1-\beta)\left(4 k b-\Delta^{2}\right)}$, the manufacturer's profit is $\pi_{m}^{C R^{*}}=\frac{k\left((1+\beta) k+2(1-\beta)\left(2 k b-\Delta^{2}\right)\right)\left(a-(1-\beta) c_{m}\right)^{2}}{(1-\beta)\left(2 k+(1-\beta)\left(4 k b-\Delta^{2}\right)\right)^{2}}+f^{C R^{*}}$, the retailer's profit is $\pi_{r}^{C R^{*}}=\frac{k\left(k+\Delta^{2}\right)\left(a-(1-\beta) c_{m}\right)^{2}}{\left(2 k+(1-\beta)\left(4 k b-\Delta^{2}\right)\right)^{2}}-f^{C R^{*}}$. Then the total profit of CLSC reaches the level of centralized decision-making, that is $\pi_{s}^{C R^{*}}=\pi_{s}^{S^{*}}$.

In order to make all members of the CLSC accept the contract, we need to meet the following conditions: $\pi_{m}^{C R^{*}} \geq \pi_{m}^{R^{*}}, \pi_{r}^{C R^{*}} \geq \pi_{r}^{R^{*}}$, then could get the upper and lower bounds of the retailer's compensation cost $f^{C R^{*}}$ to the manufacturer:

$$
\begin{gathered}
f^{C R^{*}} \geq \underline{f}^{C R^{*}}=\frac{k^{2}\left(8 k+8 k b\left(1-\beta^{2}\right)+4 b(1-\beta)(3+\beta) \Delta^{2}+C_{1} \Delta^{2}\right)\left(a-(1-\beta) c_{m}\right)^{2}}{\left(16 k+(1-\beta)(3+\beta)\left(8 k b-\Delta^{2}\right)\right)\left(2 k+(1-\beta)\left(4 k b-\Delta^{2}\right)\right)^{2}}, \\
f^{C R^{*}} \leq \bar{f}^{C R^{*}}=\frac{k^{2}\left(64 k^{2}\left(3-4 C_{2} b+C_{4} b^{2}\right)+4 k\left(C_{3}+4 b C_{7}+12 C_{5} b^{2}\right) \Delta^{2}-\left(C_{6}+8 C_{5} b\right) \Delta^{4}\right)\left(a-(1-\beta) c_{m}\right)^{2}}{\left(16 k+(1-\beta)(3+\beta)\left(8 k b-\Delta^{2}\right)\right)^{2}\left(2 k+(1-\beta)\left(4 k b-\Delta^{2}\right)\right)^{2}}
\end{gathered}
$$

where, $11-4 \beta+\beta^{2}=C_{1}, 2-\beta-\beta^{2}=C_{2}, 47-6 \beta+7 \beta^{2}=C_{3}, 5-4 \beta-6 \beta^{2}+4 \beta^{3}+\beta^{4}=C_{4}$, $9-12 \beta-2 \beta^{2}+4 \beta^{3}+\beta^{4}=C_{5}, 67-72 \beta+6 \beta^{2}-\beta^{4}=C_{6}, 38-33 \beta-\beta^{2}-3 \beta^{3}-\beta^{4}=C_{7}$. 
Lemma 3 when the parameters in the contract $\left(w^{C R^{*}}, F^{C R^{*}}, f^{C R^{*}}\right)$ satisfy: $w^{C R^{*}}=\frac{a b k+a(1-\beta)\left(4 k b-\Delta^{2}\right)+k c_{m}(1-\beta)(2-\beta)}{(1-\beta)\left(2 k+(1-\beta)\left(4 k b-\Delta^{2}\right)\right)}, F^{C R^{*}}=\frac{2 k \Delta\left(a-(1-\beta) c_{m}\right)}{2 k+(1-\beta)\left(4 k b-\Delta^{2}\right)}, f^{C R^{*}} \in\left[\underline{f}^{C R^{*}}, \bar{f}^{C R^{*}}\right]$, the coordination of the CLSC can be realized when the retailer collecting.

\section{Conclusions}

This paper studies the pricing and coordination problems of the dual-channel CLSC composed of a manufacturer and a retailer under the background of production diseconomies, and analyze the influence of manufacture's production diseconomies, the degree of competition between sales channels on the pricing, waste product collecting and profit acquisition of members of the CLSC. The main conclusions are as follows:(1) The manufacturer's production diseconomies are adverse to the optimal pricing decision of the CLSC and the members' profits. (2) The sales channel competition between manufacturer and retailer is beneficial to the pricing decision of the CLSC and the profit acquisition of member enterprises. (3) In the process of dual-channel sales, the wholesale price of the manufacturer is equal to its direct price and less than the retail price of the retailer. At the same time, the direct sales volume of manufacturer is always more than twice that of retailer, and the gap is larger as the degree of sales competition increases. (4) Within the contract parameters that manufacturer and retailer are willing to accept, two-part tariff contracts can realize the coordination of CLSC under three collecting channels.However, for this study ,there are still many problems worth further exploration, such as considering the information asymmetry between member companies, the uncertainty of market demand and the competitive behavior of member companies at the same level.

This research is supported by the National Nature Science Foundation of China (Grant No. 71701056), and Nature Science Foundation of Heilongjiang Province (Grant No. G2018007), and Fundamental Research Foundation for Universities of Heilongjiang Province (Grant No. LGYC2018JC056).

\section{References}

1. Maiti T, Giri B C. Two-way product recovery in a closed-loop supply chain with variable markup under price and quality dependent demand[J]. International Journal of Production Economics, 2017, 183: 259-272.

2. Mollick A V. Production smoothing in the Japanese vehicle industry[J]. International Journal of Production Economics, 2004, 91(1): 63-74.

3. Rawley E, Simcoe T S. Diversification, diseconomies of scope, and vertical contracting: evidence from the taxicab industry[J]. Management Science, 2010, 56(9): 1534-1550.

4. Ha A Y, Tong S, Zhang H. Sharing demand information in competing supply chains with production diseconomies[J]. Management Science, 2011, 57(3): 566-581.

5. Zheng B, Yang C, Yang J, et al. Dual-channel closed loop supply chains: Forward channel competition, power structures and coordination[J]. International Journal of Production Research, 2017, 55(12): 3510-3527.

6. Xie J P, Zhang W S, Ling L, et al. The revenue and cost sharing contract of pricing and servicing policies in a dual-channel closed-loop supply chain[J]. Journal of Cleaner Production, 2018, 191(8): 361-383. 
7. He P, He Y, Xu H. Channel structure and pricing in a dual-channel closed-loop supply chain with government subsidy[J]. International Journal of Production Economics, 2019, 213: 108-123.

8. Savaskan R C, Bhattacharya S, Wassenhove L N V. Closed-loop supply chain models with product remanufacturing[J]. Management Science, 2004, 50(2): 239-252. 